\title{
Comparison of three distinct methods for the detection of circulating tumor cells in colorectal cancer patients
}

\author{
ANNALISA GERVASONI ${ }^{1}$, MARIA TERESA SANDRI ${ }^{4}$, RICCARDO NASCIMBENI $^{3}$, LAURA ZORZINO $^{4}$, \\ MARIA CRISTINA CASSATELLA ${ }^{4}$, LUIGI BAGLIONI ${ }^{1}$, SARA PANIGARA ${ }^{2}$, MARIA GERVASI $^{2}$, \\ DIEGO DI LORENZO ${ }^{2}$ and ORNELLA PAROLINI ${ }^{1}$ \\ ${ }^{1}$ Centro di Ricerca E. Menni, Fondazione Poliambulanza-Istituto Ospedaliero, Via Bissolati 57, I-25124 Brescia; \\ ${ }^{2}$ Laboratorio di Biotecnologie $/ 3^{\circ}$ Servizio Analisi, Ospedale Civile di Brescia, P.le Spedali Civili 1; ${ }^{3}$ Department of \\ Medical and Surgical Sciences, University of Brescia, Viale Europa 11, I-25123 Brescia; ${ }^{4}$ Laboratory \\ Medicine Unit, European Institute of Oncology, Via Ripamonti 435, I-20141 Milan, Italy
}

Received January 18, 2011; Accepted February 24, 2011

DOI: 10.3892/or.2011.1231

\begin{abstract}
The detection of circulating tumor cells (CTCs) has considerable utility in the clinical management of patients with solid cancers. However, the phenotypic heterogeneity of CTCs and their low numbers in the bloodstream of patients means that no standardized detection method currently exists for these cells. This, together with differences in pre-analytical sample processing, has led to the collection and accumulation of inconsistent data among independent studies. Here, we compare the ability of three methods to detect CTCs in the blood of colorectal cancer patients. Specifically, different aliquots of the same blood sample were screened for the presence of CTCs by a multimarker RT-PCR assay, the standardized CellSearch assay and dHPLC-based gene mutation analysis. In the population tested, none of the blood samples analysed appeared to be positive by all three methods. Of the samples, $75 \%$ were positive for the presence of CTCs by the RT-PCR method. Only $20 \%$ were positive by the CellSearch assay, while $14.3 \%$ of samples displayed gene mutations consistent with the presence of CTCs when the dHPLC method was applied. The samples which were positive for CTCs by the CellSearch assay did not overlap with those that were positive by dHPLC. Interestingly, however, all of these samples were positive when assessed by RT-PCR. Conversely, of the samples that resulted negative by RT-PCR analysis, none appeared to be positive by either of the other methods. These data, therefore, indicate that of the three methods tested, the
\end{abstract}

Correspondence to: Dr Ornella Parolini, Centro di Ricerca E. Menni, Fondazione Poliambulanza-Istituto Ospedaliero, Via Bissolati 57, I-25124 Brescia, Italy

E-mail: ornella.parolini@tin.it

E-mail: parolini-ornella@poliambulanza.it

Key words: circulating tumor cells, colorectal cancer, method comparison, multimarker RT-PCR assay, CellSearch assay, dHPLC, gene mutation multimarker RT-PCR assay provides maximal probability of CTC detection. Here, we present the preliminary results of an ongoing clinical study. Future follow-up involving detection of CTCs in the blood of colorectal cancer patients using these three distinct methods will allow us to verify whether either a single method, or a combination of different assays, is necessary to uncover further prognostic significance of circulating tumor cells.

\section{Introduction}

Epidemiological studies indicate that colorectal cancer is the second most prevalent malignant tumor in terms of incidence and mortality in the general population of western countries (1). The incidence in Italy is about 200,000 cases per year (FISMAD Congress 2009, Italian Federation of Digestive System Diseases) and despite curative resection as the major treatment option, about half of all patients develop distant metastases. The detection of circulating tumor cells (CTCs) in the peripheral blood of patients with different neoplastic diseases has been used as an early potential marker of the metastatic spread of malignant cells in the bloodstream (2-6), and is, therefore, considered a sign of poor prognosis (7-11). In fact, the malignant nature of CTCs has been established in previous studies by the identification of tumor-specific chromosomal aberrations (2) and other genetic changes $(12,13)$, as well as by their in vitro growth with cancer cell-like behaviour (14). In addition, in several studies the number of CTCs detected seems to correlate with the aggressiveness of different advanced malignancies, such as breast $(9,15,16)$, prostate $(17,18)$ and colorectal cancer (19). Moreover, detectable CTCs at the end of chemotherapy was found to be associated with an increased risk of relapse and death (Rack BK, J Clin Oncol, 2008 ASCO Proc; 20,21). Independent studies have also reported a significant genetic heterogeneity among early disseminated tumor cells in breast cancer patients, demonstrating the existence of a subpopulation of CTCs with putative stem cell phenotypes in patients with metastatic breast cancer which are either associated (22) or not (23) with worse patient outcome, partially 
supporting the hypothesis that tumor progression and resistance to chemotherapy is dependent on a group of cells that share stem cell features (24).

Several techniques have been used to detect CTCs, some analysing tissue- or tumor-specific gene expression (25-28) or genome mutation analysis (29), detecting CTCs as intact cells, such as by the CellSearch System. This last method is the only system approved for clinical use by the American Food and Drug Administration (9,30). Interestingly, it was observed that the ability of early changes in CTC numbers to predict the outcome in metastatic breast cancer patients undergoing a new therapy was at least as good as that of traditional radiologic evaluation (31) and also that the CTC assay was more reproducible and more informative than radiographic interpretation. In another study, the prognostic value of CTC detection was also superior to FDG-PET imaging in metastatic breast cancer patients (32).

However, the lack of a standardized method to detect CTCs, that is, differences in preanalytical sample processing and differences in analytical methods, produced inconsistent results among different studies $(26,27)$. The discrepancies were mainly observed in the proportion of CTC-positive patients and in the number of detectable cells.

In order to identify the most effective way to detect CTCs, a few studies compared different enrichment techniques and methods for detection of CTCs in the blood of breast cancer $(33,34)$, prostate cancer $(35)$ and other metastatic carcinoma patients $(36,37)$, sometimes showing concordance in results between methods of analysis or variation in CTC detection rates due to the higher sensitivity of the molecular methodology utilized in the analysis $(33,34)$.

In this study we compared three distinct techniques to detect CTCs in the peripheral blood of patients undergoing surgery for colorectal cancer, in order to investigate whether a single method or a combination of different methods may offer a more sensitive and specific approach to the detection and enumeration of CTCs in patient samples. Specifically, different aliquots of the same blood sample were screened for CTCs by: a highly sensitive multimarker RT-PCR assay, previously described by Gervasoni et al (38), the standardized and regulatory-approved CellSearch assay, and a dHPLC-based gene mutation analysis. Secondly, we evaluated the association between the presence of CTCs and clinical-pathological variables.

\section{Materials and methods}

Patient characteristics. The study was conducted in 20 patients undergoing elective surgery for colorectal adenocarcinoma between November 2008 and December 2009. Written informed consent was obtained from each patient enrolled in the study according to the guidelines of the Ethics Committee of the Catholic Hospital (CEIOC).

Exclusion criteria were the following: urgent or emergency surgical procedure, synchronous or previous colorectal cancer, co-existence of adenomatous polyposis, ulcerative colitis or Crohn's disease.

The following patient and tumor variables were prospectively recorded: age and gender, tumor site (right colon, left colon and rectum), stage (as defined according to TNM
Table I. Patient, tumor and treatment variables (20 subjects, 19 tumor specimens available).

\begin{tabular}{|c|c|c|}
\hline Variable & Values & No. of patients \\
\hline \multicolumn{3}{|l|}{ Patient age (years) } \\
\hline Median & 70.5 & \\
\hline Range & $53-84$ & \\
\hline \multicolumn{3}{|l|}{ Patient gender } \\
\hline Male & 15 & \\
\hline Female & 5 & \\
\hline \multicolumn{3}{|l|}{ Tumor site } \\
\hline Right colon & & 7 \\
\hline Left colon & & 6 \\
\hline Rectum & & 7 \\
\hline \multicolumn{3}{|l|}{ Tumor stage } \\
\hline I & & 5 \\
\hline II & & 8 \\
\hline III & & 6 \\
\hline IV & & 1 \\
\hline \multirow{2}{*}{\multicolumn{3}{|c|}{$\begin{array}{l}\text { Grade of cellular } \\
\text { differentiation }\end{array}$}} \\
\hline & & \\
\hline Grade 1 & & 1 \\
\hline Grade 2 & & 15 \\
\hline Grade 3 & & 4 \\
\hline Mucinous variant & & 3 \\
\hline Signet ring cell & & 0 \\
\hline Circumferential margin & & 0 \\
\hline \multicolumn{3}{|l|}{ involvement } \\
\hline Lymphatic invasion & & 8 \\
\hline Vascular invasion & & 1 \\
\hline Tumor budding & & 14 \\
\hline Palliative surgery & & 2 \\
\hline Chemoradiation & & 13 \\
\hline
\end{tabular}

definitions and AJCC groupings), grade of cellular differentiation, mucinous or signet ring cell variants, circumferential margin involvement, presence of lymphatic or vascular invasion and tumor budding. The following treatment variables were prospectively recorded: intent of surgery (palliative or curative, depending on the presence or absence of macroscopic residual disease at the end of surgical treatment) and chemoradiation prior or after surgery (performed or not). The characteristics of the study cohort according to these variables are summarized in Table I.

Sampling of biological material. Before surgery, peripheral blood samples were obtained from each patient, drawn into distinct collection tubes and processed independently with the three distinct CTC detection methodologies as described in the following sections. Five 5-ml EDTA-containing tubes were processed for multimarker molecular expression, one 5-ml serum tube and one 5-ml EDTA-containing tube were analysed for gene mutation detection, and one 7.5-ml CellSave tube (CellSave Preservative Tubes, Veridex 
Table II. Marker panel with forward and reverse primers, annealing temperatures, product sizes and references/GeneBank sequence accession numbers.

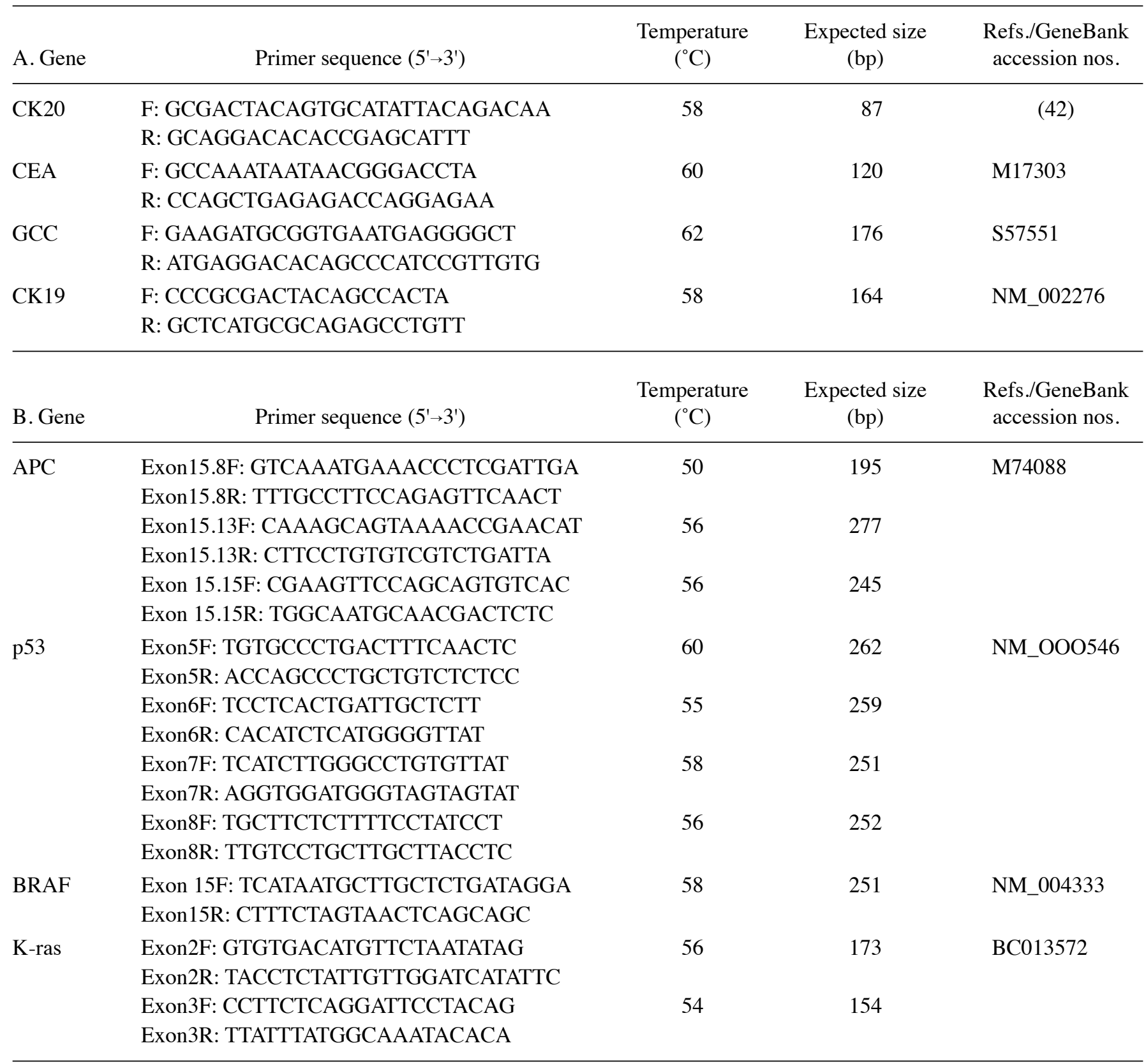

LLC, Warren, NJ, USA) was processed for CTC count by CellSearch immunomagnetic selection. To prevent contamination with epithelial cells, the first $5 \mathrm{ml}$ of blood from each patient were discarded.

Biopsies of the tumor and normal mucosa (at least $5 \mathrm{~cm}$ distant from tumor margin) were collected from each fresh surgical specimen within 20 min of detachment from the vascular supply. In one patient (Stage I, T1N0M0) no fresh tumor tissue was obtained due to the small size of the lesion $(<0.7 \mathrm{~cm}$ in diameter).

Multimarker RT-PCR assay. The molecular multimarker assay that we have developed and described in detail in a previous study (38), enables the immunomagnetic enrichment of tumor cells from the peripheral blood of cancer patients and the subse- quent RT-PCR expression analysis of 4 genes, CEA, CK20, CK19 and GCC, selected for detection of colorectal tumor cells.

Twenty-five millilitres of peripheral blood were obtained from each patient and processed within $2 \mathrm{~h}$, as previously described in detail (38). Briefly, peripheral blood mononuclear cells (PBMCs) were collected by centrifugation through a Ficoll density gradient (Lymphoprep; Axis-Shield, Oslo, Norway). Cells were then subjected to white blood cell depletion. Negative immunomagnetic selection using anti-CD45 specific antibodies (Dynabeads M-450 CD45 Pan Leukocyte, Dynal Biotech ASA, Oslo, Norway) was performed to enrich for tumor cells, according to the manufacturer's instructions. All non-bound cells, the CD45 negative (CD45) fraction (enriched in tumor cells) were collected and lysed to release RNA in $750 \mu$ l QIAzol reagent (Qiagen Inc., Valencia, CA, 
USA). Subsequently, RNA was isolated from whole blood specimens and from enriched cell fractions, reverse transcribed and analysed for the expression of CEA, GCC, CK20 and CK19 genes. Primer sequences, predicted product sizes and annealing temperatures are indicated in Table IIA. Amplification conditions were: $10 \mathrm{~min}$ at $95^{\circ} \mathrm{C}$ for $1 \mathrm{cycle} ; 30 \mathrm{sec}$ at $95^{\circ} \mathrm{C}, 40 \mathrm{sec}$ at the annealing temperature for each set of primers (Table IIA) and $30 \mathrm{sec}$ extension at $70^{\circ} \mathrm{C}$ for 45 cycles, with a final extension cycle of $7 \mathrm{~min}$ at $70^{\circ} \mathrm{C}$. For each sample and gene, 3 independent RT-PCR assays were performed. The spiked tumor cell recovery experiments performed as controls for the assay method and the sensitivity of the method are described in a previous paper (38).

CellSearch System ${ }^{T M}$. Blood samples were kept at room temperature and processed within $96 \mathrm{~h}$ after collection. The CellSearch System was used to detect the presence of CTCs. The method has been described in detail elsewhere (30). Briefly, ferrofluid particles conjugated to anti-EpCAM antibodies are used for the isolation of EpCAM positive cells, using a magnetic field. After removing the supernatant, the cells are fluorescently stained using 4',6-diamidino-2-phenylindole (DAPI) for nucleic acid, anti-cytokeratin-phycoerythrin for epithelial cells, and allophycocyanin-conjugated anti-CD45 antibody to detect and exclude leucocytes. Stained cells are then analyzed on a fluorescence microscope that automatically scans the surface of the reaction cartridge, and CTCs are defined as nucleated cells (DAPI positive) lacking CD45 but expressing cytokeratins (CKs). The presence of 1 or more cells per $7.5 \mathrm{ml}$ of blood was considered a positive result.

Mutation detection. Specific genomic mutations were first assessed in patient tumor tissues. The gene mutations identified were then followed in whole blood, serum samples and cDNAs from PBMCs of the same patient. Genomic DNA was extracted from $200 \mu \mathrm{l}$ of EDTA-anticoagulated blood by use of the QIAamp DNA Blood Mini Kit (Qiagen spa, Milan) according to the manufacturer's instructions (Qiagen) from normal and tumor tissue samples by a desalting $\mathrm{NaCl}$ extraction method. Primers for PCR amplifications of specific gene fragments were obtained from MWG Biotech (M.Medical srl, Cornaredo, Mi). The specific primer sequences for amplifying the different gene mutations are reported in Table IIB.

PCR reactions were carried out in a 50- $\mu 1$ volume with $100 \mathrm{ng}$ of template genomic DNA, $200 \mu \mathrm{M}$ each of the deoxynucleotide triphosphates, $10 \mathrm{mM}$ Tris- $\mathrm{HCl}(\mathrm{pH} 8.3), 50 \mathrm{mM}$ $\mathrm{KCl}, 2 \mathrm{mM} \mathrm{MgCl}$, $1.5 \mathrm{U}$ of AmpliTaq Gold (Applera Italia, Monza) and 25 pmol of each primer.

DHPLC mutation analysis. Heteroduplexes were obtained by denaturing the PCR products at $94^{\circ} \mathrm{C}$ for $10 \mathrm{~min}$ and cooling at $56^{\circ} \mathrm{C}$ for $60 \mathrm{~min}$. Mutation analysis was performed according to a previously described method $(39,40)$ on a Transgenomic WAVE System (Transgenomic, NE, USA) equipped with a preheated C18 reversed-phase column based on non-porous polystyrene/ divinylbenzene particles (DNASep ${ }^{\mathrm{TM}}$; Transgenomics). For UV detection, $8 \mu \mathrm{l}$ of the PCR mixture was injected into the column, and the heteroduplexes and homoduplexes were eluted with a linear gradient formed by mixing buffer A $(0.1 \mathrm{~mol} / \mathrm{l}$ triethylamine acetate, $\mathrm{pH} 7.0)$ and buffer $\mathrm{B}(0.1 \mathrm{~mol} / \mathrm{l}$ triethylamine acetate, $\mathrm{pH} 7.0$, containing $250 \mathrm{ml} / 1$ acetonitrile) at a constant flow rate of $0.9 \mathrm{ml} / \mathrm{min}$. DNA was detected by monitoring the absorbance at $260 \mathrm{~nm}$. For each fragment, the initial and final concentrations of buffer $\mathrm{B}$ were adjusted to obtain a retention time between 3 and $5 \mathrm{~min}$. The column was then washed with $100 \%$ buffer B for $30 \mathrm{sec}$ and equilibrated at starting conditions for $1 \mathrm{~min}$. The melting characteristics of the DNA fragments were predicted by use of the Wavemaker ${ }^{\mathrm{TM}}$ software (Transgenomic Ltd., Glasgow). Following UV detection, a DNA-intercalating dye (WAVE Optimized HS Staining Solution I; Transgenomic) was mixed with the eluted sample to increase the sensitivity and measured by fluorescence with excitation at $490 \mathrm{~nm}$ and emission at $520 \mathrm{~nm}$, according to the instructions of the manufacturer. A 100-fold higher sensitivity was obtained compared to UV reading. Gene variants with altered elution profiles in AHPLC were sequenced directly in both directions with the appropriate primers.

Sensitivity of mutation detection using DNA from MYH mutant patients. The sensitivity of heteroduplex detection on the WAVE HS system was tested by means of dilution curves. An MYH fragment containing the heterozygous mutation IVS6+35A was diluted with white blood cells, which did not express the MYH mutation as they were obtained from a healthy donor. Genomic DNA was isolated from cell mixtures containing 100, 10, 1, 0.1 or $0 \%$ mutant cells.

To confirm that the mutant allele could be identified, these samples were fractionated using partially denaturating high-performance liquid chromatography (dHPLC). Under these conditions, heteroduplexes were eluted first. To enrich for heteroduplexes, the first fractions from the chromatogram were collected and sequenced. dHPLC analysis of the fractions isolated from $100,10,1,0.1$ or $0 \%$ dilutions of the $\mathrm{MYH}$ (IVS6+35A) could detect the mutation (by UV) only in the samples containing 100 and $10 \%$ of mutant DNA (not shown). Using fractionation, re-amplification and sequencing we were able to enrich for the mutant-containing heteroduplex PCR product by at least 4-fold.

The DNA fragment MYH (IVS6+35A) was amplified and fractionated on the WAVE HS system using the highsensitivity fluorescence detector, with WAVE Optimized Staining Solution I. With this method the mutant allele is easily detected in the $100 \%$ mutant DNA (double peak) and remains visible in genomic DNA mixtures containing as little as $1-0.1 \%$ of mutant DNA.

Statistical analysis. We evaluated the association between each of the three methods (positive for CTCs vs. negative) with all the clinicopathologic characteristics using the Fisher's exact test. We decided not to report any measure of agreement between tests because of the evident variability in the detection rates of positive samples. For that reason we have reported all the individual results and a descriptive analysis of the agreement.

\section{Results}

CTC detection by single methods. The data obtained from three independent RT-PCR assays for CTC marker expression are summarized in Table III. Using this first method of molecular analysis, a total of $15(75 \%)$ out of 20 patient samples 
Table III. Comparative data of CTC detection using the three methods: CellSearch assay, molecular expression and oncogene mutation detection in blood, serum and cDNA samples.

\begin{tabular}{|c|c|c|c|c|c|c|c|}
\hline \multirow{2}{*}{$\begin{array}{l}\text { Patient } \\
\text { ID }\end{array}$} & \multicolumn{5}{|c|}{ Mutation detection } & \multirow[b]{2}{*}{$\mathrm{cDNA}^{\mathrm{a}}$} & \multirow[b]{2}{*}{ Cells ${ }^{\mathrm{b}}$} \\
\hline & Tumoral tissue & Normal tissue & Blood & Serum & cDNA & & \\
\hline \multirow[t]{3}{*}{1} & APC EX15.30 & APC EX15.30 & APC EX15.30 & APC EX15.30 & APC EX15.30 & + & + \\
\hline & $\mathrm{A}>\mathrm{T} \mathrm{nt} 5465$ & $\mathrm{~A}>\mathrm{T} \mathrm{nt} 5465$ & $\mathrm{~A}>\mathrm{T} \mathrm{nt} 5465$ & $\mathrm{~A}>\mathrm{T}$ nt5465 & $\mathrm{A}>\mathrm{T} \mathrm{nt} 5465$ & & \\
\hline & D1822VD1822V & D1822V & D1822V & D1822V & & & \\
\hline 2 & $\begin{array}{l}\text { APC EX15.15 C>G } \\
\text { nt } 4031 \text { S1344STOP }\end{array}$ & No mutation & No mutation & No mutation & No mutation & - & - \\
\hline 3 & $\begin{array}{l}\text { APC EX15.32 del T } \\
\text { nt5799 1969STOP }\end{array}$ & No mutation & No mutation & No mutation & No mutation & + & - \\
\hline 4 & $\begin{array}{l}\text { APC EX } 15.15 \text { C }>\text { T } \\
\text { nt } 4099 \text { Q1367STOP }\end{array}$ & No mutation & No mutation & No mutation & No mutation & + & - \\
\hline 5 & $\begin{array}{l}\text { p53 EX7 G>T nt } 734 \\
\text { G245V p53 EX8 C >T } \\
\text { nt } 916 \text { R306STOP }\end{array}$ & No mutation & No mutation & No mutation & No mutation & + & - \\
\hline 6 & No mutation & I & 1 & 1 & I & + & - \\
\hline 7 & No mutation & I & l & I & I & + & + \\
\hline 8 & $\begin{array}{l}\text { APC EX } 15.9 \\
\text { delAA nt3186-87 } \\
\text { E1064STOP }\end{array}$ & No mutation & No mutation & No mutation & No mutation & + & - \\
\hline 9 & $\begin{array}{l}\text { APC EX15.30 } \\
\text { A>T nt5465 } \\
\text { D1822V omo }\end{array}$ & $\begin{array}{l}\text { APC EX15.30 } \\
\text { A>T nt5465 } \\
\text { D1822V omo }\end{array}$ & $\begin{array}{l}\text { APC EX15.30 } \\
\text { A>T nt5465 } \\
\text { D1822V omo }\end{array}$ & $\begin{array}{l}\text { APC EX15.30 } \\
\text { A>T nt5465 } \\
\text { D1822V omo }\end{array}$ & $\begin{array}{l}\text { APC EX15.30 } \\
\text { A>T nt5465 } \\
\text { D1822V omo }\end{array}$ & + & + \\
\hline 10 & $\begin{array}{l}\text { p53 EX 4:5' C>G } \\
\text { nt466 P72R }\end{array}$ & $\begin{array}{l}\mathrm{C}>\mathrm{G} \text { nt } 466 \\
\mathrm{P} 72 \mathrm{R}\end{array}$ & $\begin{array}{l}\mathrm{C}>\mathrm{G} \text { nt } 466 \\
\mathrm{P} 72 \mathrm{R}\end{array}$ & $\begin{array}{l}\mathrm{C}>\mathrm{G} \text { nt } 466 \\
\mathrm{P} 72 \mathrm{R}\end{array}$ & l & - & - \\
\hline 11 & $\begin{array}{l}\text { p53 EX7 C>A } \\
\text { nt705 N235K }\end{array}$ & No mutation & $\begin{array}{l}\text { p53 EX7 C>A } \\
\text { nt705 N235K }\end{array}$ & $\begin{array}{l}\text { p53 EX7 C>A } \\
\text { nt705 N235K }\end{array}$ & I & + & - \\
\hline 12 & $\begin{array}{l}\text { BRAF T>A nt } 1799 \\
\text { V600E p53 EX7 C >A } \\
\text { nt705 N235K }\end{array}$ & No mutation & $\begin{array}{l}\text { p53 EX7 C>A } \\
\text { nt705 N235K }\end{array}$ & $\begin{array}{l}\text { p53 EX7 C>A } \\
\text { nt705 N235K }\end{array}$ & I & + & - \\
\hline 13 & $\begin{array}{l}\text { APC EX15.15 delGT } \\
\text { nt4160-61 1394X }\end{array}$ & No mutation & No mutation & No mutation & I & + & - \\
\hline 14 & $\begin{array}{l}\text { APC EX15.13 delTT } \\
\text { nt3783-84 1275X }\end{array}$ & No mutation & No mutation & $\begin{array}{l}\text { APC EX15.13 delTT } \\
\text { nt3783-84 1275X }\end{array}$ & I & + & - \\
\hline 15 & $\begin{array}{l}\text { p53 EX } 8 \text { C > T nt817 } \\
\text { R273C T>G nt4128 } \\
\text { Y1376X }\end{array}$ & No mutation & No mutation & No mutation & & - & - \\
\hline 16 & No mutation & l & I & I & I & - & - \\
\hline 17 & $\begin{array}{l}\text { p53 EX 4:5' del C } \\
\text { nt518 128X }\end{array}$ & No mutation & No mutation & No mutation & I & - & - \\
\hline 18 & $\begin{array}{l}\text { K-ras EX2 G>T } \\
\text { nt35 G12V }\end{array}$ & No mutation & No mutation & No mutation & I & + & - \\
\hline 19 & No tissue & 1 & I & 1 & I & + & - \\
\hline 20 & $\begin{array}{l}\text { p53 EX4:5' C>G } \\
\text { nt466 P72R omo }\end{array}$ & $\begin{array}{l}\mathrm{C}>\mathrm{G} \text { nt466 } \\
\mathrm{P} 72 \mathrm{R} \text { omo }\end{array}$ & $\begin{array}{l}\mathrm{C}>\mathrm{G} \text { nt } 466 \\
\mathrm{P} 72 \mathrm{R} \text { omo }\end{array}$ & $\begin{array}{l}\mathrm{C}>\mathrm{G} \text { nt466 } \\
\mathrm{P} 72 \mathrm{R} \text { omo }\end{array}$ & I & + & - \\
\hline
\end{tabular}

${ }^{a}$ CDNA presence $(+)$ or absence (-) as detected by molecular expression analysis; ${ }^{b}$ Presence $(+)$ or absence $(-)$ of CTCs as detected by the CellSearch System. 
were observed to be positive for CTC marker expression. In particular, when considering the CD45-negative fraction, 9 out of these were positive for CEA, 10 patients were positive for CK19, 4 patients for CK20 and 4 patients for the GCC marker. We also observed that 2 patients were double positive for CEA and CK19 transcript expression, 1 patient for CK19 and CK20, 2 patients were positive for both CEA and CK20, 1 patient for CEA and GCC, 2 patients were triple positive for CEA, CK19 and GCC, and 1 for CEA, CK20 and GCC. Five patients (25\%) were CTC negative with this method.

The data obtained by dHPLC screening of hotspot regions of the APC, p53, K-ras and BRAF genes (see Material and methods) in tissue samples, whole blood and serum of patients are shown in Table III. Mutant DNA was identified in $71 \%$ of the tumor tissue samples analysed. The mutations observed in patient tumor samples were then identified in whole blood and serum to follow the presence of tumor cells by detection of mutant DNA or mutation-free DNA. A total of 15 patients were positive for mutations in one of the 4 gene fragments analysed from tumor tissues. Of these, 2 patient samples (P11, P12) were found to be positive in both whole PBMCs and serum and one (P14) only in the serum sample. From patient 12 we found two different mutations (BRAF V600E and p53 N235K) in the tumor tissue, but only one in whole blood and serum (p53 N235K). Four patients (P1, P9, P10, P20) showed positive in all samples indicating a germline mutation. Thus, these are not suitable to assess disease recurrence and follow-up. Using the CellSearch System, CTCs were detected in 3 patients $(20 \%)$ : 2 patients $(\mathrm{P} 1, \mathrm{P} 7)$ presented $1 \mathrm{CTC} / 7.5 \mathrm{ml}$ of whole blood, while 1 patient $(\mathrm{P} 9)$ presented 2 CTCs/7.5 ml of whole blood.

CTC detection by combined methods. We observed variability in the detection rates of positive samples using the three different techniques: $14.3 \%$ (3/20) of patient samples with colon cancer were positive for CTCs by the CellSearch System, 20\% (3/15) by the gene mutation detection method and $75 \%(15 / 20)$ using multimarker RT-PCR.

The three patient samples that tested positive with the CellSearch System and the three patient samples in which the dHPLC-based assay showed the presence of the same CTC-associated oncogene mutations in blood, serum or cDNA from PBMCs as that detected in tumor tissue, were also positive by the RT-PCR analysis (Table III). No blood sample analysed tested positive by all three methods.

Correlation between CTC detection and clinicopathologic factors. None of the considered clinicopathologic parameters of the study cohort (Table I) showed a significant correlation with one or more methods applied to detect the CTCs.

\section{Discussion}

The detection and enumeration of CTCs have considerable potential in the clinical management of patients with solid cancers. However, CTCs are phenotypically heterogeneous cells, that are rare in the blood of cancer patients. Therefore, different techniques have been developed and have been used in combination in efforts to maximize the ability to detect and identify CTCs.
In this study, for the first time to our knowledge, we compared three CTC detection methods, two based on a molecular approach (one based on tumor marker transcript analysis, and one based on the detection of gene mutations) and one based on a cytofluorometric technique, the CellSearch System. We found that the detection rate was higher for the RT-PCR-based method for 4 tumor associated markers $(75 \%$ of patient samples were positive by this method) compared with the other two approaches, which presented a much lower detection rate (14.3 or $20 \%$ of the samples were positive).

Our first goal was to compare the methods of CTC detection and then to possibly identify and maximize the possibility of CTC detection by combination of one or more of the methods.

Few studies have compared the performance of different methods for CTC detection in the same population and even fewer included patients with colon cancer $(36,37)$. It is well known that the PCR assays show a higher sensitivity compared to the cytofluorometric approach. In fact, a recent paper by Van der Auwera et al (33) showed that in patients with metastatic breast cancer, the CTC positive rate was higher when a qRT-PCR approach for the detection of CK19 and mammoglobin was used compared to other systems like CellSearch or Adnagen, approved CTC detection method. In our population sample, the highest rate of positive samples was observed using the RT-PCR approach (75\% positive samples). The data suggest that this method might be the most sensitive method for detecting CTCs among the three methods under study. Interestingly, all 3 blood samples positive for tumor cells using the CellSearch System and the 3 samples displaying gene mutations were also positive by the RT-PCR analysis assay. None of the 5 CTC-marker negative samples were positive by either CellSearch or dHPLC. On the other hand, we observed that in blood samples of patients with detectable tumor cells by the CellSearch System, no mutations were identified in circulating DNA by the dHPLC analysis, since no pathogenetic sporadic mutations were found in these tumors. The mutations identified in the blood of three patients were not confirmed by cellular detection using CellSearch. The variability of CTC detection among the three methods may be explained by the fact that the tumor cells disseminated in blood might be heterogeneous and therefore, certain types might not be identified by the CellSearch method either because it is based on anti-EpCAM antibody enrichment (41), or because with this system only intact cells are counted. This might certainly be considered a positive characteristic, as damaged cells will likely not be able to enter into the tissues and metastasize. It is also noteworthy, that the low detection rate with dHPLC may be explained by the fact that specific dHPLC assays can be applied to patient blood samples only if a gene mutation is previously identified in the patient tumor tissue. Actually, in 4 (P1, P9, P10 and P20) out of 20 patients, no mutations could be identified in the analysed genes beyond the reported germinal mutations.

Another possible explanation of these discrepancies in the data observed using different CTC detection methodologies is probably due to the different volumes of blood required for the distinct investigation methodologies. Indeed, CTCs are rarely found in peripheral blood of cancer patients, therefore, it is likely that larger volumes of blood have to be processed to increase the probability of tumor cell identification and consequently to improve the sensitivity of the assay. 
Our comparative data also revealed that there is a partial overlap in positive results regarding the detection rate of tumor cells obtained using the multimarker RT-PCR assay and either the CellSearch assay or the gene mutation analysis. The data show that the multimarker RT-PCR assay is likely to be the method that provides the highest chance of CTC detection in the peripheral blood of colorectal patients. In particular, we also observed that this molecular method allowed identification of tumor cells in patients with more advanced stages (TNM 3 and 4), with respect to TNM 1 or 2 patients. However, none of the three CTC detection methods showed a significant correlation with any of the clinicopathologic parameters analysed for the study cohort and recorded in Table I.

Herein we have presented the preliminary comparative data of a clinical study that is still ongoing. During further clinical follow-up, the detection of CTCs in the blood of colorectal cancer patients by the three distinct techniques will allow us to verify whether either a single method or a combination of different methods exhibits better prognostic significance for CTC detection.

\section{Acknowledgments}

This study was supported in part by AIRC (Associazione Italiana Ricerca sul Cancro) IG 8649.

\section{References}

1. Boyle P and Ferlay J: Cancer incidence and mortality in Europe, 2004. Ann Oncol 16: 481-488, 2005.

2. Fehm T, Sagalowsky A, Clifford E, et al: Cytogenetic evidence that circulating epithelial cells in patients with carcinoma are malignant. Clin Cancer Res 8: 2073-2084, 2002.

3. Guadagni F, Kantor J, Aloe S, et al: Detection of blood-borne cells in colorectal cancer patients by nested reverse transcription-polymerase chain reaction for carcinoembryonic antigen messenger RNA: longitudinal analyses and demonstration of its potential importance as an adjunct to multiple serum markers. Cancer Res 61: 2523-2532, 2001.

4. Chen XM, Chen GY, Wang ZR, Zhu FS, Wang XL and Zhang X: Detection of micrometastasis of gastric carcinoma in peripheral blood circulation. World J Gastroenterol 10: 804-808, 2004.

5. Hampton R, Walker M, Marshall J and Juhl H: Differential expression of carcinoembryonic antigen (CEA) splice variants in whole blood of colon cancer patients and healthy volunteers: implication for the detection of circulating colon cancer cells Oncogene 21: 7817-7823, 2002.

6. Ring A, Smith IE and Dowsett M: Circulating tumour cells in breast cancer. Lancet Oncol 5: 79-88, 2004.

7. Guller U, Zajac P, Schnider A, et al: Disseminated single tumor cells as detected by real-time quantitative polymerase chain reaction represent a prognostic factor in patients undergoing surgery for colorectal cancer. Ann Surg 236: 768-766, 2002.

8. Weigelt B, Bosma AJ, Hart AA, Rodenhuis S and van 't Veer LJ: Marker genes for circulating tumour cells predict survival in metastasized breast cancer patients. Br J Cancer 88: 1091-1094, 2003 .

9. Cristofanilli M, Budd GT, Ellis MJ, et al: Circulating tumor cells, disease progression, and survival in metastatic breast cancer. N Engl J Med 351: 781-791, 2004.

10. Cristofanilli M, Hayes DF, Budd GT, et al: Circulating tumor cells: a novel prognostic factor for newly diagnosed metastatic breast cancer. J Clin Oncol 23: 1420-1430, 2005.

11. Cristofanilli M, Broglio KR, Guarneri V, et al: Circulating tumor cells in metastatic breast cancer: biologic staging beyond tumor burden. Clin Breast Cancer 7: 471-479, 2007.

12. Austrup F, Uciechowski P, Eder C, et al: Prognostic value of genomic alterations in minimal residual cancer cells purified from the blood of breast cancer patients. Br J Cancer 83: $1664-1673,2000$.
13. Soria JC, Gauthier LR, Raymond E, et al: Molecular detection of telomerase-positive circulating epithelial cells in metastatic breast cancer patients. Clin Cancer Res 5: 971-975, 1999.

14. Reinhold U, Ludtke-Handjery HC, Schnautz S, Kreysel HW and Abken H: The analysis of tyrosinase-specific mRNA in blood samples of melanoma patients by RT-PCR is not a useful test for metastatic tumor progression. J Invest Dermatol 108: 166-169, 1997.

15. Nole F, Munzone E, Zorzino L, et al: Variation of circulating tumor cell levels during treatment of metastatic breast cancer: prognostic and therapeutic implications. Ann Oncol 19: 891-897, 2008.

16. Pierga JY, Bidard FC, Mathiot C, et al: Circulating tumor cell detection predicts early metastatic relapse after neoadjuvant chemotherapy in large operable and locally advanced breast cancer in a phase II randomized trial. Clin Cancer Res 14: 7004-7010, 2008.

17. Danila DC, Heller G, Gignac GA, et al: Circulating tumor cell number and prognosis in progressive castration-resistant prostate cancer. Clin Cancer Res 13: 7053-7058, 2007.

18. De Bono JS, Scher HI, Montgomery RB, et al: Circulating tumor cells predict survival benefit from treatment in metastatic castration-resistant prostate cancer. Clin Cancer Res 14: 6302-6309, 2008.

19. Cohen SJ, Punt CJ, Iannotti N, et al: Relationship of circulating tumor cells to tumor response, progression-free survival, and overall survival in patients with metastatic colorectal cancer. J Clin Oncol 26: 3213-3221, 2008

20. Apostolaki S, Perraki M, Pallis A, et al: Circulating HER2 mRNA-positive cells in the peripheral blood of patients with stage I and II breast cancer after the administration of adjuvant chemotherapy: evaluation of their clinical relevance. Ann Oncol 18: 851-858, 2007.

21. Xenidis N, Ignatiadis M, Apostolaki S, et al: Cytokeratin-19 mRNA-positive circulating tumor cells after adjuvant chemotherapy in patients with early breast cancer. J Clin Oncol 27: 2177-2184, 2009.

22. Ginestier C, Hur MH, Charafe-Jauffret E, et al: ALDH1 is a marker of normal and malignant human mammary stem cells and a predictor of poor clinical outcome. Cell Stem Cell 1: 555-567, 2007.

23. Theodoropoulos PA, Polioudaki H, Agelaki S, Kallergi G, Saridaki Z, Mavroudis D and Georgoulias V: Circulating tumor cells with a putative stem cell phenotype in peripheral blood of patients with breast cancer. Cancer Lett 288: 99-106, 2010.

24. Trumpp A and Wiestler OD: Mechanisms of Disease: cancer stem cells - targeting the evil twin. Nat Clin Pract Oncol 5: 337-347, 2008.

25. Zach O and Lutz D: Tumor cell detection in peripheral blood and bone marrow. Curr Opin Oncol 18: 48-56, 2006.

26. Zieglschmid V, Hollmann C and Bocher O: Detection of disseminated tumor cells in peripheral blood. Crit Rev Clin Lab Sci 42: 155-196, 2005

27. Paterlini-Brechot $\mathrm{P}$ and Benali NL: Circulating tumor cells (CTC) detection: clinical impact and future directions. Cancer Lett 253: 180-204, 2007.

28. Schuetz CS, Bonin M, Clare SE, et al: Progression-specific genes identified by expression profiling of matched ductal carcinomas in situ and invasive breast tumors, combining laser capture microdissection and oligonucleotide microarray analysis. Cancer Res 66: 5278-5286, 2006.

29. Takayama T, Miyanishi K, Hayashi T, Sato Y and Niitsu Y: Colorectal cancer: genetics of development and metastasis. J Gastroenterol 41: 185-192, 2006.

30. Allard WJ, Matera J, Miller MC, et al: Tumor cells circulate in the peripheral blood of all major carcinomas but not in healthy subjects or patients with non-malignant diseases. Clin Cancer Res 10: 6897-6904, 2004

31. Budd GT, Cristofanilli M, Ellis MJ, et al: Circulating tumor cells versus imaging - predicting overall survival in metastatic breast cancer. Clin Cancer Res 12: 6403-6409, 2006.

32. De Giorgi U, Valero V, Rohren E, et al: Circulating tumor cells and [18F]fluorodeoxyglucose positron emission tomography/ computed tomography for outcome prediction in metastatic breast cancer. J Clin Oncol 27: 3303-3311, 2009.

33. Van der Auwera I, Peeters D, Benoy IH, et al: Circulating tumour cell detection: a direct comparison between the CellSearch System, the AdnaTest and CK-19/mammaglobin RT-PCR in patients with metastatic breast cancer. Br J Cancer 102: 276-284, 2010. 
34. Deng G, Herrler M, Burgess D, Manna E, Krag D and Burke JF: Enrichment with anti-cytokeratin alone or combined with anti-EpCAM antibodies significantly increases the sensitivity for circulating tumor cell detection in metastatic breast cancer patients. Breast Cancer Res 10: R69, 2008.

35. Helo P, Cronin AM, Danila DC, et al: Circulating prostate tumor cells detected by reverse transcription-PCR in men with localized or castration-refractory prostate cancer: concordance with CellSearch assay and association with bone metastases and with survival. Clin Chem 55: 765-773, 2009.

36. Balic M, Dandachi N, Hofmann G, et al: Comparison of two methods for enumerating circulating tumor cells in carcinoma patients. Cytometry B Clin Cytom 68: 25-30, 2005.

37. Konigsberg R, Gneist M, Jahn-Kuch D, et al: Circulating tumor cells in metastatic colorectal cancer: efficacy and feasibility of different enrichment methods. Cancer Lett 293: 117-123, 2010.
38. Gervasoni A, Monasterio Munoz RM, Wengler GS, Rizzi A, Zaniboni A and Parolini O: Molecular signature detection of circulating tumor cells using a panel of selected genes. Cancer Lett 263: 267-279, 2008

39. Xiao W and Oefner PJ: Denaturing high-performance liquid chromatography: a review. Hum Mutat 17: 439-474, 2001.

40. Cremonesi L, Stenirri S, Fermo I, Paroni R, Ferrari M, Cazzola $\mathrm{M}$ and Arosio P: Denaturing HPLC analysis of DNA deletions and insertions. Hum Mutat 22: 98-102, 2003.

41. Sieuwerts AM, Kraan J, Bolt J, et al: Anti-epithelial cell adhesion molecule antibodies and the detection of circulating normal-like breast tumor cells. J Natl Cancer Inst 101: 61-66, 2009.

42. Bustin SA, Siddiqi S, Ahmed S, Hands R and Dorudi S: Quantification of cytokeratin 20, carcinoembryonic antigen and guanylyl cyclase $\mathrm{C}$ mRNA levels in lymph nodes may not predict treatment failure in colorectal cancer patients. Int J Cancer 108: 412-417, 2004. 